\title{
Visualization of job availability based on text analytics localization approach
}

\author{
Nur Azmina Mohamad Zamani ${ }^{1}$, Norhaslinda Kamaruddin ${ }^{2}$, Abdul Wahab ${ }^{3}$, Nur Shahana Saat ${ }^{4}$ \\ ${ }^{1,4}$ Faculty of Computer and Mathematical Sciences, Universiti Teknologi MARA Perak Branch, Malaysia \\ ${ }^{2}$ Advanced Analytics Engineering Centre, Faculty of Computer and Mathematical Sciences, \\ Universiti Teknologi MARA, Malaysia \\ ${ }^{3}$ Kulliyah of Information and Communication Technology, International Islamic University Malaysia, Malaysia
}

\begin{tabular}{|c|c|}
\hline Article Info & ABSTRACT \\
\hline Article history: & \multirow{10}{*}{$\begin{array}{l}\text { Rate of employment is a strong indicator of economic stability that relates to } \\
\text { the services and products. One of the main factors that contributes to low rate } \\
\text { employment is the mismatch between job seeker and the job requirement due } \\
\text { to the limited analysis performed on the job advertisement. The obscure job } \\
\text { descriptions may result in application of unsuitable candidates that can cause } \\
\text { candidate rejection and time consuming. In this paper we proposed a text } \\
\text { analytics technique to extract users' comments from social media on job } \\
\text { advertisement. The result is then displayed in a geotagged map that can } \\
\text { reveal the density of job availability based on geographical location. The job } \\
\text { seekers can easily observe and select their desired job location. The initial } \\
\text { system shows potential of the inclusion of the proposed approach in job } \\
\text { advertisement websites. In comparison to other job searching websites, this } \\
\text { system can provide additional information on public view about the } \\
\text { advertised job obtained from the social media text analytics. It is hoped that } \\
\text { the proposed system can tailor the job advertisements to the need of the } \\
\text { jobseeker and making the job application more relevant hence reducing the } \\
\text { potential employers' processing time. }\end{array}$} \\
\hline Received Jan 9, 2019 & \\
\hline Revised Apr 7, 2019 & \\
\hline Accepted May 2, 2019 & \\
\hline Keywords: & \\
\hline Job searching & \\
\hline Job seekers' sentiment & \\
\hline Localization & \\
\hline Text analytics & \\
\hline Visualization & \\
\hline
\end{tabular}

Copyright (C) 2019 Institute of Advanced Engineering and Science. All rights reserved.

\author{
Corresponding Author: \\ Norhaslinda Kamaruddin, \\ Advanced Analytics Engineering Centre, \\ Faculty of Computer and Mathematical Sciences, \\ Universiti Teknologi MARA, \\ 40450 Shah Alam, Selangor. \\ Email: norhaslinda@tmsk.uitm.edu.my
}

\section{INTRODUCTION}

Rate of unemployment can be defined as the percentage of unemployed worker in total labor force. It is a strong indicator of economic stability of a country and relates strongly to the number of volumes of produced products and services. The individuals who are without job, actively looking for a job over a period of time and are currently available for work are known as unemployed [1]. This is as opposed to people with a job for pay or profit that are called employed. Nonetheless, the individuals who are neither employed nor unemployed are not included in the labor force. The unemployment rate can be used to measure the economic wealth of a country [2]. If the unemployment rate is high, the amount of gross domestic product (GDP) of a country may be declined. It may also affect the purchasing power since the unemployed may have limited ability to pay the price of products and services which cause businesses to obtain less profits. This situation may result to another cycle of unemployment for other workers. Such scenario may create downward trend to the economic stability. Moreover, according to [3], high unemployment rate will cause unhappiness that leads to riot and high level of unsatisfaction. The amount of works to be completed are still the same with lesser workers to execute the tasks with no additional salary. The remained workers may also feel 
uncomfortable and guilty when their subordinates are being fired. Hence, it is not surprising to observe that higher unemployment rate leads to a more negative impacts on economy of a nation [4].

Based on the statistic provided by Department of Statistic Malaysia (DOSM) [5], Malaysia ranked the 35 th country in the world with $3.3 \%$ unemployment rate. Figure 1 illustrates the top 50 countries that recorded the least unemployment rate and Table 1 presented 10 selected countries that have unemployment rate within $4.0 \%$. The 10 selected countries that have unemployment rate within $4.0 \%$ are Qatar, Thailand, Vietnam, Singapore, Japan, Hong Kong, Germany, Malaysia, China and United States. Qatar recorded the least unemployment rate with $0.1 \%$ followed by Cambodia and Belarus with both countries recorded the unemployment rate of $0.3 \%$. Three South East Asia countries; Laos, Myanmar and Thailand recorded the unemployment rates of $0.7 \%, 0.8 \%$ and $1.0 \%$ respectively making these three countries at the position of 5th, 6 th and 7th in the world unemployment rate ranking. Vietnam and Singapore are at the 17th and 18th position with the unemployment rate of $2.19 \%$ and $2.20 \%$. Both the United States and United Kingdom yielded the unemployment rate of $4.0 \%$. Zooming to Malaysia unemployment rate from 2010 till 2018, it is observed that Malaysia recorded mixed results ranging from $3.00 \%$ to $3.45 \%$. as shown in Table 2 . The lowest unemployment rate for Malaysia is logged in 2014 and 2015 with $3.00 \%$ and on contrary, the highest unemployment rate was recorded in 2016 with 3.45\%. DOSM also reported that 14.99 million of Malaysian working age population ranging from 15 years old to 64 years old are employed whereas 7.12 million Malaysian were considered as outside labor force (as of December 2018) [5-6]). The outside labor force typically comprises of housewives, students, retirees and those who are not interested to work.

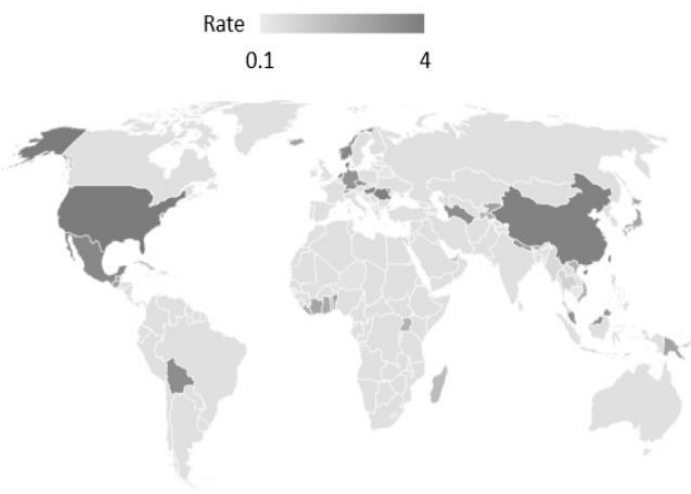

Figure 1. Top 50 countries with unemployment rate of less than $4.0 \%$

Table 1. Selected Countries within the Top 50 Countries with Unemployment Rate Less than 4.0\%

\begin{tabular}{ccc}
\hline Rank & Country & UR \\
\hline 1 & Qatar & 0.10 \\
7 & Thailand & 1.00 \\
17 & Vietnam & 2.19 \\
18 & Singapore & 2.20 \\
22 & Japan & 2.50 \\
30 & Hong Kong & 2.80 \\
34 & Germany & 3.20 \\
35 & Malaysia & 3.30 \\
48 & China & 3.80 \\
50 & United States & 4.00 \\
\multicolumn{3}{c}{$*$ UR= Unemployment Rate } \\
\hline \multicolumn{3}{c}{}
\end{tabular}

Table 2. Statistic on Malaysia's Unemployment Rate from 2010 to 2018 [6]

\begin{tabular}{cccccccccc}
\hline Country & 2010 & 2011 & 2012 & 2013 & 2014 & 2015 & 2016 & 2017 & 2018 \\
\hline Malaysia & 3.30 & 3.05 & 3.03 & 3.10 & 3.00 & 3.00 & 3.45 & 3.43 & 3.30 \\
\hline
\end{tabular}

The youth unemployment in Malaysia is reported to be more than three times higher (10.7\%) than the national unemployment rate in $2015(3.00 \%)$ [7]. The youth aged 15 to 24 years old comprises of $61 \%$ of unemployment in Malaysia where only $16 \%$ of these youths undergo tertiary education and the rest only possessed primary, secondary and no formal education. However, the report also presented that non-tertiary youth $(2,162,000$ individuals) have lower unemployment rate of $9.8 \%$ with difference of $5.5 \%$ with tertiary

Visualization of job availability based on text analytics localization approach (Norhaslinda Kamaruddin) 
educated youth (405,000 individuals). This is due to the job creation in Malaysian economy is basically concentrated in the low and mid-skills jobs [8] and constantly focused on cost efficiency and cheap labor. In addition, a study by MIDF Research reported that $86.3 \%$ of job vacancies in 2017 is low-skill job and not suitable for a fresh graduate [9]. Based on the Graduate Tracer Study report by Ministry of Education [10], the main factor of unemployment is still seeking for a job. Almost $70 \%$ to $75 \%$ of the participants stated that the reason that they are unemployed is because they are still seeking for a job ranging from 37,316 graduates in 2017 to 39,864 graduates in 2013 [11]. Other factors are presented in Figure 2 such as taking a break, waiting for placement to further study, responsibility towards family, jobs offered not suitable, choose not to work, not interested to work, lack of self-confidence to face working environment, health problem, refuse to move to another place and other reasons. In a different study, the reasons of youth unemployment are; namely, unrealistic salary and below expectation benefits (72\%), choosy about job and organization (64\%), low English proficiency (59\%) and poor communication skills (53\%) [12].

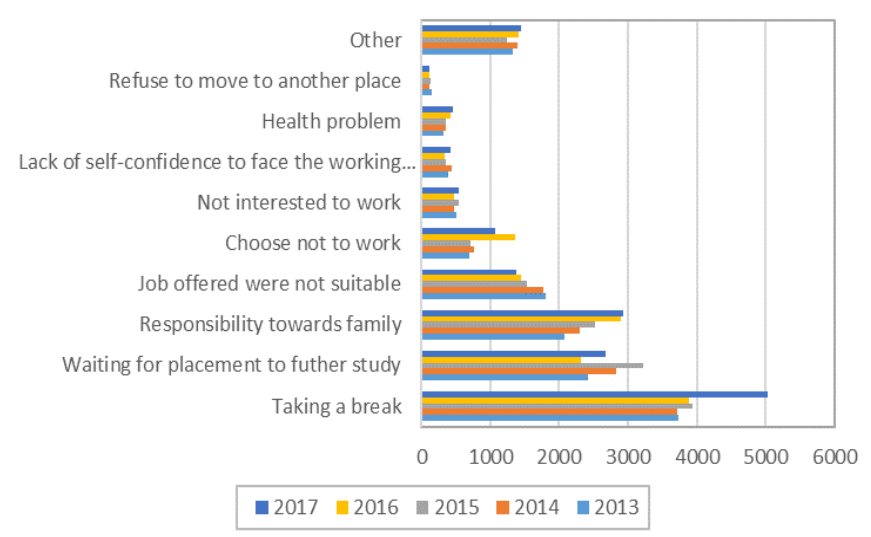

Figure 2. Factors of graduate unemployment in Malaysia from 2013 and 2018 [11]

The struggles faced by jobseekers are not only on the lack of skills that they must have to compete with other candidates but also the scarcity of market information and limited job search experience [12-14]. Usually, information on job advertisements are obtained via word-of-mouth from families and friends [13] which provides very limited information on the jobs available. According to R. J. McGovern, direct advertisements in the employment section of newspapers or magazines are mostly targeted for experienced jobseekers [15]. The available job searching websites are limited as the small and medium enterprises (SMEs) may not register their job vacancies. Moreover, job advertisement on the job searching websites are not that user friendly to use making the digital illiterate youths make feel crippled and uncomfortable and the result of relevant searches may not be properly presented.

One of the most important factors that the job seekers need to consider is the placement of the job. The ownership of transportation, the traveling cost, the availability of public transportations and parking slot are the parameters that need to be calculated when applying for a job. For the low-income group who stay in rural area with limited public transportation services, placement of the job plays a big role in deciding factor of accepting or rejecting a job offer. Hence in this work, we propose to visualize the job location using geotagged map visualization technique to be embedded in the job searching website so that it can facilitate the jobseekers to make an informed decision when applying for a post.

This paper is organized in the following manner. Section 2 describes the typical ways of searching job online of either finding a job through job searching website or social media networks. The explanation of the method used to develop the job availability visualization based on users' sentiments on social media is provided in Section 3. The expected result is presented in Section 4. The paper concludes in Section 5 with discussion on the potential of the proposed approach implementation in job searching websites to facilitate jobseekers to find job online.

\section{ONLINE JOB SEARCHING}

Jobseekers find job online by accessing job searching websites such as JobStreet [16], LinkedIn [17], Indeed [18], Monster [19] and other available platforms. These websites provide a platform for the 
jobseeker to find a suitable job and potential employers to advertise job or position that they need to hire [11]. However, not all companies register their job advertisements through such website because the employers need to pay a certain amount of service fee. Moreover, the search result of the job searching website usually in text form for location of the job advertisement that needs the jobseekers to open different applications to see the geographical location such as Google Maps [20]. The results of the search are very specific of the user that does not allow any sharing of the information and any discussions or opinions are not considered.

Most existing job searching websites has similar features. Table 3 presented the comparison between the available job searching websites with the proposed approach. It is observed that all three available job searching websites display the search results in a traditional way of using text descriptions. There is no geotagged location that show the exact location of the job using the geographical map. Although Monster offers sharing features, both JobStreet and Indeed did not provide for such function. Subsequently, the opinions and discussion of the jobseekers are not even considered in all available job searching websites. However, as mentioned earlier, SMEs may advertise their job vacancy through social media, hence, the relevant information can be extracted and enriched the search result of the proposed system.

Table 3. Summary of Job Searching Site Comparisons

\begin{tabular}{|c|c|c|c|c|c|}
\hline \multirow{2}{*}{ SITE } & \multicolumn{5}{|c|}{ ELEMENTS } \\
\hline & Job Description & Location & Geotagged Location & Sharing Function & Opinions and Discussions \\
\hline JobStreet & 1 & 1 & $\mathrm{x}$ & $\mathrm{x}$ & $\mathrm{x}$ \\
\hline Indeed & l & l & $\mathrm{x}$ & $\mathrm{x}$ & $\mathrm{x}$ \\
\hline Monster & l & l & $\mathrm{x}$ & I & $\mathrm{x}$ \\
\hline Proposed Work & 1 & I & I & I & 1 \\
\hline
\end{tabular}

Social media has become an important platform for obtaining and sharing information in different domains, such as business, entertainment, science, crisis management and politics [21]. As an alternative to job searching websites, companies and potential employers can advertise their job vacancies through social media platforms such as Twitter [22], Facebook [23] and LinkedIn [17]. The advantages of using such platforms is that it is free and can access many users. The richness of variety of data types in social media such as textual data, images, videos, sounds and geolocations are some example of data type formats that the social media platforms can offer. Registered Facebook users in Malaysia is 22.7 million and it is the most popular social media in Malaysia as compared to other platforms [24]. Potential employers can advertise their job vacancy through their wall that will be displayed in the newsfeed. Jobseekers can directly message or write comments in the job vacancy advertisement posts. In addition, the usage of hashtags making Twitter as one of the most useful resources for job searching. Employers can post the job vacancies and using unique hashtags to enable jobseekers to easily find the job. Subsequently, 94\% of recruiters use LinkedIn as the top social media resource to choose candidates making the platform as the number one ranked jobseeker social media platform [25]. LinkedIn offers services such as right criteria filtering, email relevant job posting alert and job application making it as a favourite of the jobseekers and potential employers.

The data from these social media can be extracted. For instance, Twitter REST APIs can be employed to collect data from the identified Twitter accounts of the communities that can return up to 3200 of users most recent Tweets [26]. In addition, the Online Social Network Retrieval Systems (OSNRS) is a tool developed to decentralize the retrieving system that uses Multi Agent System (MAS) technology which can monitor profiles continuously and involves replacing the parser with the Application Programming Interface (API) tool [27]. In this work, information on job advertisements are obtained from the Twitter and Facebook page of Jobs Perak to observe others' opinions and discussions on the job vacancy.

\section{RESEARCH METHODOLOGY}

Our method consists of several components that requires data extraction from job advertisements from the employers as well as the users' comments gathered from social media and data visualization. In this work, inputs are collected from the Twitter and Facebook page of Jobs Perak. The proposed visualization job availability based on text analytics localization approach is presented in Figure 3. Based on Figure 3, the process starts with employers from different companies in Malaysia will post available jobs on a social media page and job searching websites. Based on the specific advertisement of a job vacancy, social media users may give opinions and comments on the particular job that is being advertised. All the information on jobs including the coordinates being tagged on social media will be extracted together with the user comments. All the information on jobs and users' comments are extracted. The coordinates are geotagged with the job description on the map according to the location of the workplace. The texts extracted from the user

Visualization of job availability based on text analytics localization approach (Norhaslinda Kamaruddin) 
comments are processed to be displayed. Then, the data will be visualized by plotting markers on the map of Perak including markers containing the job description. Each marker represents one job information involving the job scope, requirements, location and users' opinion regarding the job. The comments of social media users will be displayed at the side of the map whenever a location marker is clicked showing the opinions about the selected job.

Job searching websites usually post information on job scopes and location of the workplace generally which makes the jobseekers unable to pin-point the exact location. However, the use of geotagged data in Facebook and Twitter are common. Locations information are sometimes provided by the users to post statuses or photos via mobile phones. It is observed that most social media users tend to update their posts online using mobile phones that is equipped with GPS which produced huge geotagged datasets [28]. This work uses the D3 visualization tool to assist in producing the graphical representation of the locations from the job advertisements retrieved. The locations tagged with the job information will be mapped onto the visualized map based on its coordinates. The output will show the job description when the tagged location (marker) is clicked. Scatter plot is also applied on a D3 map to have an overview on which area has the most job vacancies using D3 tool.

Therefore, by providing the location marker on the map allow jobseekers to have better estimation of the distance between their home and the workplace. In addition, in order to get an overview of the job's environment, user comments on Facebook and Twitter give jobseekers some ideas about the company staffs as well as the nature of the job they are going to apply. Hence, a more comprehensive understanding can be gained by the job seekers before they gauged the suitability of the job vacancy applications.

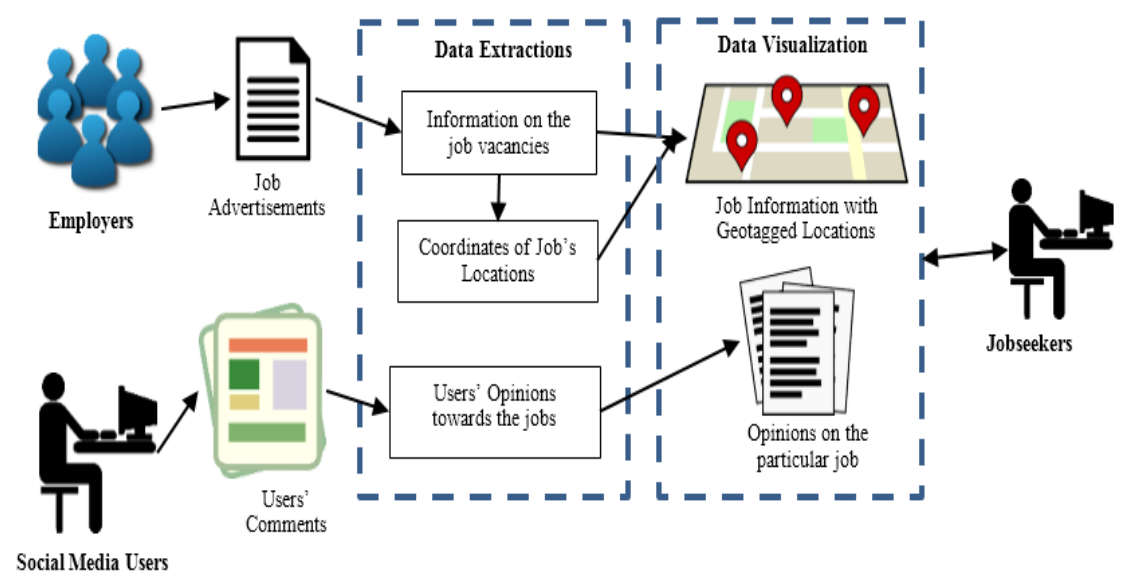

Figure 3. System overview of the proposed visualization job availability based on text analytics localization job recommender system

\section{EXPECTED RESULT OF VISUALIZATION JOB AVAILABILITY BASED ON TEXT ANALYTICS LOCALIZATION APPROACH}

Visualization is the process of representing data in a form of informational graphics to make it easier for people to interpret the data. Method of visualization refers to the fact that after the first data is transformed to visualization elements, complex resource content is designated in vivid and intuitionistic appearance for better understanding. From a numerous posting about jobs from the social media, important information is gathered in a platform to provide a more meaningful information for jobseekers to choose the most suitable job for them. In this proposed work, the relevant information is gathered and incorporated with job information with geotagged location for comprehensive understanding of the job advertisements.

Geotagging is a process of adding geographical information to various media in a form of metadata consisting of latitude and longitude data, as well as bearing, altitude, distance and place names. Typically geotagging is used for photographs and presented a lot of specific data about the location of the picture was taken or the exact location of a friend who logged on to a service. For example, the checked-in function in Facebook. Some types of geographical representation involve scatter-plot diagram, spatial or geographic visualization, parallel coordinates, tree map and many more. Based on [29] work, spatial representations are being used the most for information visualization, where the major source of inspiration for spatial visualization is the geographic information system (GIS). Besides plotting the graph on a plain map, [30] 
work uses the Google Map API to retrieve the map and geotagged the locations on the map from a collection of millions geotagged pictures by building the location probability maps for tag annotations over the entire globe.

Figure 4 illustrates the Google Map representation with geotagged location of job vacancies available in Perak based on the number of markers being tagged on the map using a designing tool called MockFlow. Each marker on the map indicates the job vacancy information at the location. When the specific location is selected by user, it will display the job scope, workplace, direction to the workplace and also users' opinion about the job. A "share" function is also available to share job's advertisements online via social media. This function enables further accessibility to more audience of the job advertisements. In addition, there is also a function to direct the user to the Google Map application to assist them in finding out the distance from their accommodation to the workplace. This is important for the jobseekers who have high dependency on transportation.

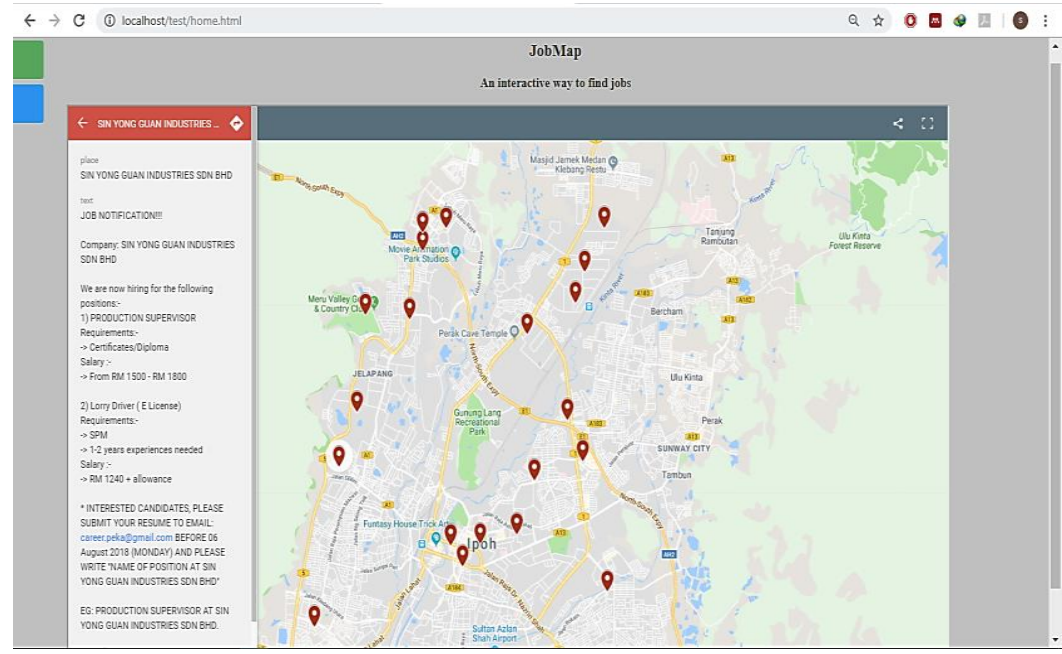

Figure 4. Visualized jobs information on map

From the view in Figure 4, a summarized graphical representation will be displayed as shown in Figure 5 that provides an overall view of the geotagged location on the map. Scatter plots technique is used to represent each location of the jobs on the map. This visualization technique allows jobseekers to directly observe the area with the most job opportunities. Moreover, user can also read and gauge the other people comments and opinions on the advertised job to give some ideas to the jobseekers of the future workplace in terms of the staffs' behavior, working environment and the nature of the job despite observing the density of job applications in a specific area.

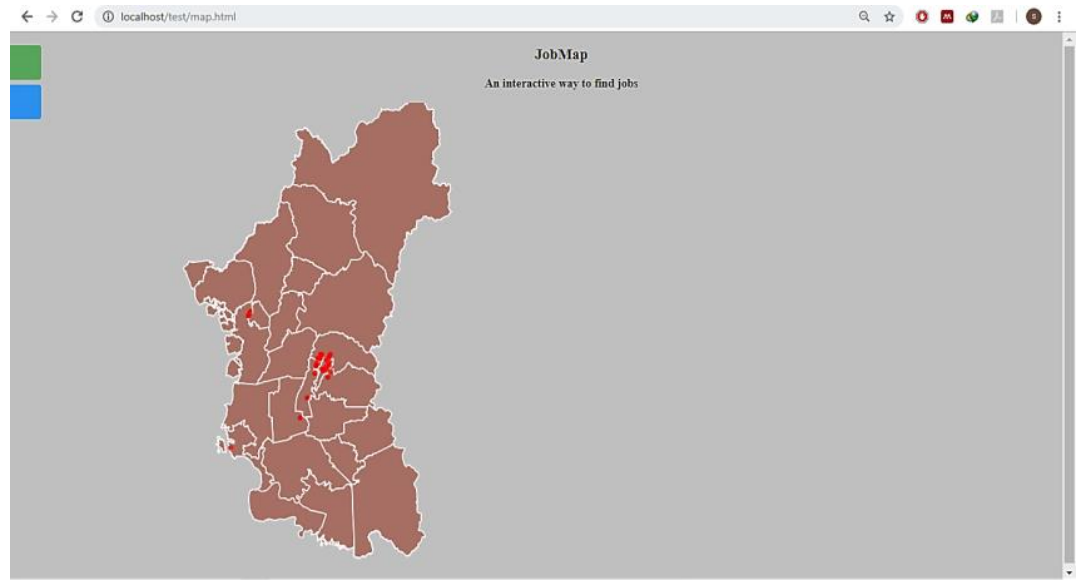

Figure 5. Summarized graphical representation 


\section{CONCLUSION}

This work focuses on providing detailed information on job advertisements by locations with reference to social media data such as jobs information being posted, location of the workplace and public opinions about the job or the workplace environment. The data are firstly collected from Twitter and Facebook page. All job advertisements and its location coordinates are stored in a database. Then, each location is being tagged by using markers for the user to select on the area to view the job descriptions. As a result, a D3 map consisting of scatter plots will be shown besides the original map in order to observe the area with the most job vacancies. Hence, this system aims to enhance the proposed interface by adding positive and negative indicator towards the jobs being advertised based on the texts obtained from public comments. Subsequently, it is envisaged that the implementation of the proposed approach can facilitate the jobseekers job searching task and shorten the time needed by the employers to select the right candidates for the job interview process. This system can also be incorporated with learning analytics system [31] that can link the education achievement and skill of the job seeker for the job application.

\section{REFERENCES}

[1] K. Amadeo., "Bureau of Labor Statistics, What It Does, And Its Impact" [Internet], the balance, 9 November 2018, Available from: https://www.thebalance.com/bureau-of-labor-statistics-3305992.

[2] W. Kenton., "Unemployment" [Internet], Investopedia, 28 March 2018, Available from: https://www.investopedia.com/terms/u/unemployment.asp.

[3] M. I. Hossain, et al., "Factors Influencing Unemployment among Fresh Graduates: A Case Study in Klang Valley," International Journal of Academic Research in Business \& Social Sciences, vol. 8(9), pp. 1494-1507, Sep 2018.

[4] pohnpei397., "What is the impact of unemployment on society?" [Internet], enotes, 25 August 2015, Available from: https://www.enotes.com/homework-help/what-impact-unemployment-society-493219.

[5] "Key Statistics of Labour Force in Malaysia, December 2018" [Internet], Department of Statistics Malaysia, Official Portal, $11 \quad$ February $2019, \quad$ Available from: https://www.dosm.gov.my/v1/index.php?r=column/cthemeByCat\&cat=124\&bul_id=Wks0L3pvKzJvSVdrMUhoU G1VNTIRdz09\&menu_id=U3VPMldoYUxzVzFaYmNkWXZteGduZz09.

[6] L. Ventura., "Unemployment Rates Around the World 2018," GLOBAL FINANCE, 31 October 2018, Available from: https://www.gfmag.com/global-data/economic-data/worlds-unemployment-ratescom.

[7] D. H. M. Ibrahim, et al., "Youth Unemployment in Malaysia: Developments and Policy Considerations" [Annual Report], Outlook and Policy in 2017, Available from: http://www.bnm.gov.my/files/publication/ar/en/2016/cp04_003_box.pdf.

[8] L. P. Jun., "Malaysia's Labour Market and Job Creation under the Economic Transformation Plan (ETP) 2011 to 2015," 2016.

[9] MIDF Research., "Youth Unemployment Rate Remains High as Skills Mismatch Stay Prevalent," Economic Review: 2017 Labour Market, 2018.

[10] B. Ahmad., "LAPORAN KAJIAN PENGESANAN GRADUAN" [Online], 19 July 2016, Available: https://www.mohe.gov.my/muat-turun/awam/statistik/190-laporan-kajian-pengesanan-graduan. [Accessed 23 Mac 2018].

[11] N. Kamaruddin, A. Wahab \& R. A. M. Lawi., "Jobseeker-industry Matching System using Automated Keyword Selection and Visualization Approach," Indonesian Journal of Electrical Engineering and Computer Science, vol. 13(3), pp. 1124-1129, 2019.

[12] N. Balakrishnan., "Survey Reveals Top Five Reasons Why Many Malaysian Youths Are Unemployed" [Internet], 23 August 2017, Available from: https://says.com/my/news/survey-reveals-top-five-reasons-why-so-manymalaysian-youths-are-unemployed.

[13] A. Dass, et al., "Young and jobless in Malaysia" [Online], 6 August 2018, Available from: https://www.thestar.com.my/business/business-news/2018/08/06/young-and-jobless-in-malaysia.

[14] K. C. Cheong, et al., "Employment as a journey or a destination? Interpreting graduates' and employers' perceptions - a Malaysia case study," Studies in Higher Education, vol. 43(4), pp. 702-718, 4 Jul 2016.

[15] R. J. McGovern, et al., Employment Recruiting System and method using a computer network for posting job openings and which provides for automatic periodic searching of the posted job openings, United States US 6, 370, 510, 9 Apr 2002.

[16] "Jobstreet.com" [Online], Available from: https://www.jobstreet.com.my.

[17] "Linkedin" [Online], Available from: https://www.linkedin.com.

[18] "indeed" [Online], Available from: https://www.indeed.com.my.

[19] "monster" [Online], Available from: https://www.monster.com.my.

[20] "Google Maps" [Online], Available from: https://www.google.com/maps.

[21] S. Stieglitz, et al., "Social media analytics-Challenges in topic discovery, data collection, and data preparation," International Journal of Information Management, vol. 39, pp. 156-168, Apr 2018.

[22] "Twitter" [Online], Available from: https://twitter.com.

[23] "Facebook" [Online], Available from: https://www.facebook.com.

[24] "Statista" [Internet], "Number of Facebook users in Malaysia from 2017 to 2023 (in millions)", The Statistics Portal, Available from: https://www.statista.com/statistics/490484/number-of-malaysia-facebook-users. 
[25] University of Essex., "6 ways social media can hekp you get a job" [Online], University of Essex Online Blog, Available from: https://online.essex.ac.uk/blog/6-ways-social-media-can-help-get-job.

[26] M. Komorowski, et al., "Twitter data analysis for studying communities of practice in the media industry," Telematics and Informatics, vol. 35(1), pp. 195-212, Apr 2018.

[27] R. Abdulrahman, et al., "Data Extraction from Online Social Networks Using Application Programming Interface in a Multi Agent System Approach," Transactions on Computational Collective Intelligence XI, vol. 8065, pp. 88-118, 2013.

[28] A. Chua, et al., "Mapping Cilento: Using geotagged social media to characterize tourist flows in southern Italy," Tourism Management, vol. 57, pp. 295-310, 2016.

[29] R. K. Yeh., "Visualization techniques for data mining in business context: a comparative analysis," Proceedings from Decision Science Institute, pp. 310-320, 2016.

[30] J. P. Kumar, et al., "Inferring Location from Geotagged Photos," International Journal of Advanced Research in Computer Science and Software Engineering, vol. 4(9), pp. 902-906, Sep 2014.

[31] M. Hamiz, M. Bakri, N. Kamaruddin \& A. Mohamed., "Assessment Analytic Theoretical Framework Based on Learners' Continuous Learning Improvement," Indonesian Journal of Electrical Engineering and Computer Science (IJEECS), vol. 11(2), pp. 682-7, 2018.

\section{BIOGRAPHIES OF AUTHORS}

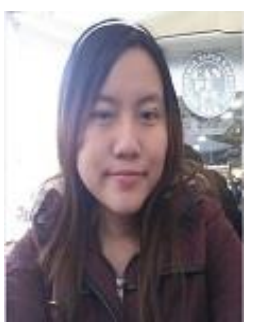

Nur Azmina received her Diploma in Computer Science from Universiti Teknologi MARA (UiTM), Malaysia in 2012 and Bachelor's Degree of Computer Science from Universiti Teknologi MARA (UiTM), Malaysia in 2014. Then, she obtained her Masters in Advanced Computer Science from The University of Sheffield, United Kingdom in 2016. Currently, she is a lecturer at Universiti Teknologi MARA (UiTM) Perak Branch, Tapah Campus, Malaysia and has been serving since 2017. Most of her researches involved Sentiment Analysis and Text Processing.

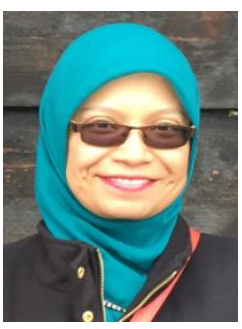

Assoc. Prof. Ts. Dr. Norhaslinda currently holds a post of associate professor in Faculty of Computer and Mathematical Sciences, Universiti Teknologi MARA (UiTM), Malaysia. She served UiTM since 2011. She received her bachelor's degree in Information Technology (Computer Science) from Universiti Kebangsaan Malaysia in 2001 followed by her Master of Software Engineering from Malaya University in 2006. In 2013, she is awarded with Doctor of Philosophy (Computer Engineering) from Nanyang Technological University (Singapore) focusing on computational intelligence especially on Affective Computing. She is very active in research fields of affective computing, speech emotion recognition, neuro-cognitive informatics and driver behavioral study.

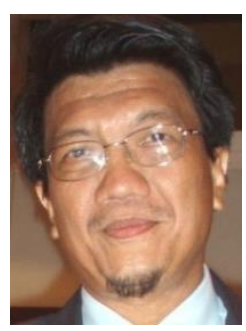

Abdul Wahab received the Degree from the University of Essex, Essex, U.K., in 1979, the M.Sc. degree from the National University of Singapore, Singapore, in 1987, and the Ph.D. degree from Nanyang Technological University, Singapore. His research has been in the areas of telecommunication, signal processing, and artificial intelligence. He was with Hewlett Packard Singapore, Singapore, as a Research and Development Project Manager both in CO, USA. He joined Nanyang Technological University in 1990, where he was an Associate Professor, before joining the International Islamic University of Malaysia, Malaysia, as a Professor, in 2009. He has authored over 100 conference papers, journal papers, patents, and book chapters in the areas of digital and optical computing, signal processing, and artificial intelligence.

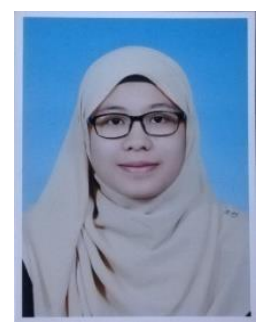

Nur Shahana Binti Saat graduated from Universiti Teknologi MARA (UiTM) Perlis with a Diploma in Computer Science in 2017. She is now a final-year student in Bachelor of Computer Science (Hons.) at Universiti Teknologi MARA (UiTM) Perak Branch, Tapah Campus, Malaysia. 